\title{
Enhancing access to cervical and colorectal cancer screening for women in rural and remote northern Alberta: a pilot study
}

\author{
Silvina C. Mema MD MSc, Huiming Yang MD MSc, Sherry Elnitsky MA CE, Zhichang Jiang MMath, \\ Marcus Vaska MLIS, Linan Xu MSc
}

Abstract

Background: Women in rural and remote northern Alberta access breast cancer screening through a mobile mammogram program (Screen Test). The Enhanced Access to Cervical and Colorectal Cancer Screening (EACS) project was a 2-year pilot that aimed to integrate cervical and colorectal cancer screening with the Screen Test program. This study compares cervical and colorectal cancer screening uptake among women screened through the pilot (Screen Test-EACS) versus Screen Test.

Methods: Screen Test-EACS was offered between 2013 and 2015 in selected rural and remote sites, with a focus on hard-toreach women living in First Nations, Métis and Hutterite communities. Participation in cervical and colorectal cancer screening was analyzed for Screen Test and Screen Test-EACS participants 6 weeks before clients received their mammogram and then again 3 months after.

Results: A total of 8390 and 1312 women participated in Screen Test and Screen Test-EACS, respectively. Screen Test-EACS significantly increased uptake of cervical (10.1\% v. $27.5 \%)$ and colorectal (10.9\% v. $22.5 \%)$ cancer screening, increasing the prevalence of women up to date with screening from $52.5 \%$ to $62.9 \%$ for cervical cancer screening and from $37.3 \%$ to $48.7 \%$ for colorectal cancer screening.

Interpretation: Screen Test-EACS increased participation in and the overall prevalence of cervical and colorectal cancer screening among hard-to-reach clients in northern Alberta, probably through removal of barriers to access and increased awareness. Further research should focus on balancing the benefits of increased participation with the costs and potential risks of over-screening.

creening for breast, cervical and colorectal cancer is effective in reducing cancer incidence and mortality. Medical organizations recommend screening for these cancers, ${ }^{1}$ and their recommendations have been adopted in many countries. Despite their success, population-based cancer screening programs face the challenge of overcoming geographical barriers for rural residents, who are often less likely to be reached by preventive health care services than are urban dwellers. ${ }^{2}$ Progress has been made in Canada in addressing geographic disparities in cancer screening; ${ }^{3}$ however, some disparities remain in Alberta. Patients must sometimes travel great distances to obtain services that are not available closer to home, ${ }^{2}$ and participation in cancer screening in the northern rural and remote regions of the province is consistenly lower than the provincial rates. In 2015, participation rates in breast, cervical and colorectal cancer screening were $56.7 \%, 62 \%$ and $39.2 \%$, respectively, in Alberta, compared with $48.7 \%, 56.9 \%$ and $36.1 \%$, respectively, in the northern region of the province. Like many other jurisdictions in Canada, ${ }^{4}$ Alberta added mobile mammography (Screen Test) to its breast cancer screening program in the early 1990s. The purpose of Screen Test ${ }^{5}$ was to reduce barriers ${ }^{6}$ to breast cancer screening for rural women. The program currently operates 2 mobile mammography units that serve the northern and southern parts of the province and provide services to over 100 communities each year.

In Alberta, all women aged 50 to 69 years are eligible for breast, cervical and colorectal cancer screening. All women aged 70 to 74 years are eligible for breast and colorectal cancer screening, and they may also be screened for cervical cancer if they meet certain criteria.

To further reduce barriers to cervical and colorectal cancer screening, a pilot project for cervical and colorectal cancer screening was added to Screen Test in 2013. The aim of the Enhanced Access to Cancer Screening (EACS) pilot project

Competing interests: Dr. Yang received a grant from the Public Health Agency of Canada for community-based programming during the conduct of the study.

This article has been peer reviewed.

Correspondence to: Silvina Mema, Silvina.Mema@ineriorhealth.ca

CMAJ Open 2017. DOI:10.9778/cmajo.20170055 
was not only to remove barriers to access for rural populations ${ }^{7}$ but also to offer a "one-stop shop" where women accessing breast cancer screening could also access cervical and colorectal cancer screening provided they were eligible as per provinical guidelines. ${ }^{8-10}$

The Screen Test-EACS pilot was implemented in selected communities while the rest of the communities received the regular Screen Test mobile visit without EACS. Both the Screen Test-EACS pilot and Screen Test targeted women between 50 and 74 years of age. As such, the Screen Test-EACS pilot was a natural experiment that allowed a comparison of cancer screening participation outcomes between communities with and without the enhanced intervention. This study explores whether participation in the Screen Test-EACS pilot program led to increased participation in cervical and colorectal cancer screening compared with Screen Test, among women in rural and remote northern Alberta. In addition, we use an integrated measure of participation across types of cancer screening, ${ }^{11}$ namely, the proportion of women up to date for all types of cancer screening for which they are eligible.

\section{Methods}

\section{Design}

Screen Test and Screen Test-EACS operated from Nov. 1, 2013, to Oct. 31, 2015, and from Sept. 18, 2013, to Oct. 8, 2015, respectively. Screen Test was the control and offered mammography only, while Screen Test-EACS was the intervention and offered mammography as well as cervical and colorectal cancer screening to eligible women. Recall letters were sent to all clients who had participated in Screen Test in the past and who were due for breast cancer screening. For women in locations where Screen Test-EACS was scheduled, the letter also included a list of clinics that would be offering the additional screening. All Screen Test and Screen TestEACS clients included in this study received a mammogram.

Participation in cervical and colorectal screening was computed for both Screen Test and Screen Test-EACS clients at 2 points in time: 6 weeks before mammogram and 3 months after mammogram. The first point in time $(6 \mathrm{w}$ before the date of mammogram) was treated as the baseline. The net increase in the prevalence of women up to date with cervical and colorectal cancer screening was calculated as the proportion of women who were up to date 3 months after the mammogram minus the proportion of women who were up to date at baseline (6 w before mammogram). Repeat screening was defined as screening tests performed on women who were already up to date with screening for that type of cancer. The number of repeat screenings was calculated as the number of women screened during the study period (between $3 \mathrm{w}$ before and 3 mo after mammogram) minus the net increase for each type of cancer screening.

\section{Setting}

Screen Test-EACS communities were a subset of the geographic areas originally covered by Screen Test, selected on the basis of their need for cancer screening services using a readiness assessment tool that took into account local clinical and support staff capacity, physical space, the community's ability to sustain the project, the availability of cancer screening services in the community, and other unique challenges. The Screen Test-EACS pilot project aimed to improve access to screening for First Nations, Métis and Hutterite women in rural and remote communities in northern Alberta.

\section{Sample population}

Women's date of birth was used to determine eligibility, with women aged 50 to 74 years of age included in this study. The clients' unique health care number enabled determination of whether women had records of having had a Papanicolaou smear and/or either fecal occult blood test (FOBT) or fecal immunochemical test (FIT). Following provincial cancer screening guidelines, ${ }^{9}$ women with database records indicating that they had had a Pap smear within 3 years of the study period were considered up to date with cervical cancer screening; women with database records indicating that they had received either FIT or FOBT within 2 years were considered up to date with colorectal cancer screening.

\section{Data sources}

Three provincial databases (breast, cervical and colorectal) were linked to determine women's participation in multiple types of screening. The Alberta Breast Cancer Screening Program database covers more than $95 \%$ of Alberta breast cancer screening and diagnostic exam records. The Alberta physician claims database was used to find the necessary data for the missing records. Together, the 2 databases provide complete information on breast cancer screening in Alberta. The Alberta Cervical Cancer Screening Program database contains Pap test cytology results for all women aged 18 years and older who are residents of Alberta. This database is auto-populated by multiple provincial repositories, including Pap test laboratories, the Alberta Cancer Registry, Alberta Health's Person Directory and the Alberta Colposcopy Database. Finally, the Alberta Colorectal Cancer Screening Program database contains completed fecal test (FOBT/FIT) laboratory records for Alberta residents. It is auto-populated by laboratories.

\section{Statistical analysis}

$\chi^{2}$ analyses were computed to assess for significant differences in the proportion of women up to date with cervical and colorectal cancer screening among those who received a mammogram though either Screen Test or Screen TestEACS at 3 different times: 6 weeks before the date of mammogram, in the time period between 6 weeks before and 3 months after mammogram, and 3 months after mammogram. The probability of being up to date with a cancer screening test was assumed to have a binomial distribution; confidence intervals (CIs) were calculated for binomial distributions. A $p$ value less than 0.05 was considered statistically significant. All statistical analyses were conducted using SAS version 9.3. 


\section{Ethics approval}

The ethical risk of this project was assessed using a Project Ethics Community Consensus Initiative ${ }^{12}$ online decisionsupport tool to screen projects; it was determined that this project carried minimal risks and therefore ethics approval was not required.

\section{Results}

The Screen Test program visited 44 communities and held 74 clinics whereas the Screen Test-EACS pilot project visited 16 communities and held 24 clinics (Figure 1, Appendix 1, available at www.cmajopen.ca/content/5/4/E740/suppl/DC1). A total of

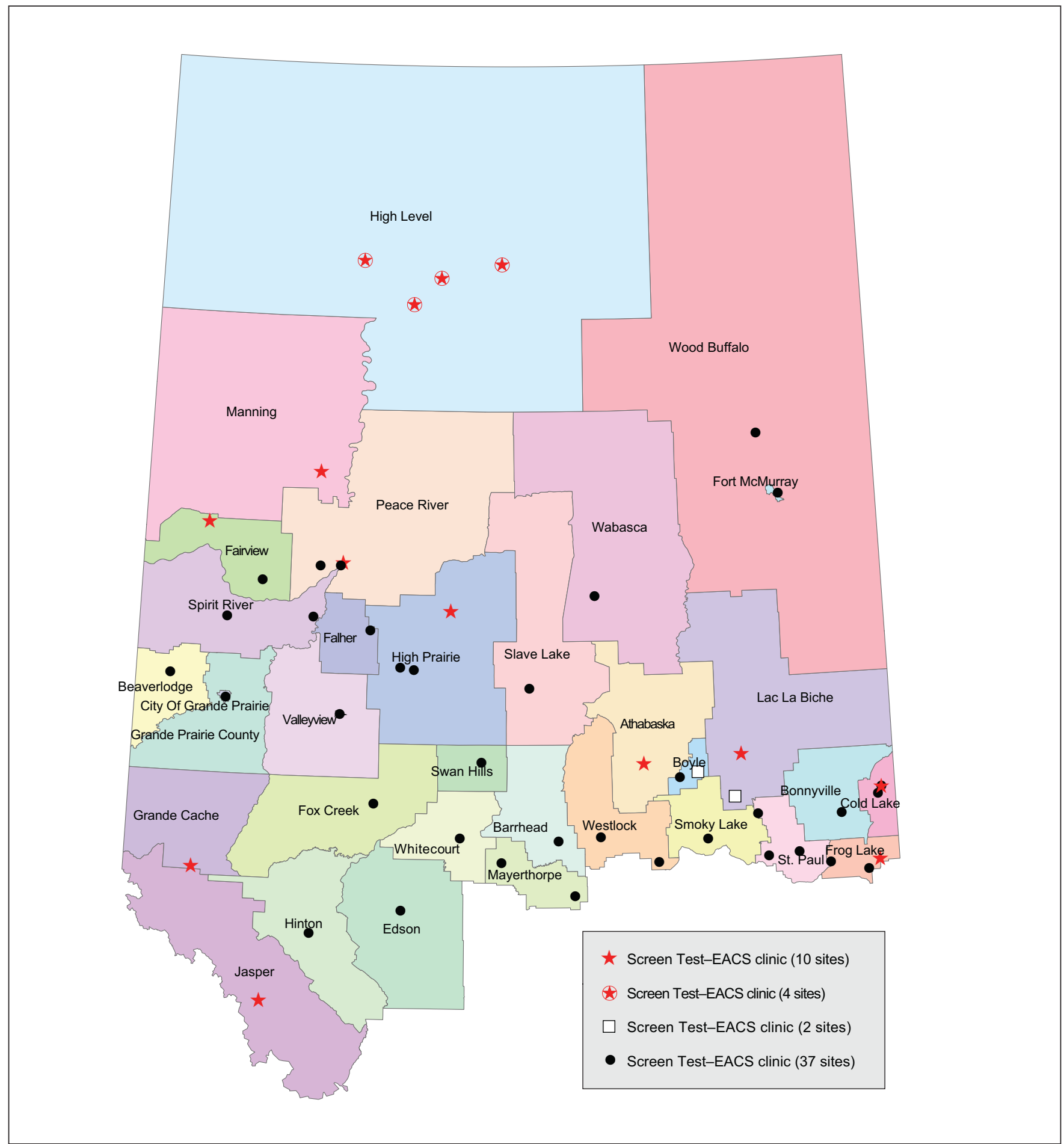

Figure 1: Locations of Screen Test and Screen Test-EACS mobile clinics. A main criterion for the selection of Screen Test-EACS locations was a lack of alternative sources of cervical and colorectal cancer screening services in rural and remote northern Alberta. 
8390 and 1312 women (including some women outside of the age range for our study cohort) had a mammogram through Screen Test and Screen Test-EACS, respectively. Of these, 6174 (73.6\%) and $958(73.0 \%)$ women were between 50 and 69 years of age at the time of mammogram and were thus considered eligible for cervical and colorectal cancer screening (Table 1).

A significantly higher $(p<0.0001)$ proportion of women were screened for cervical and colorectal cancer through Screen Test-EACS than through Screen Test as measured by all of the variables we examined, and the total number of women screened within the time period 6 weeks before to 3 months after their mammogram and the net increase in the number of clients up to date with these two types of cancer screening were also signficantly higher for the Screen Test-EACS pilot (Table 2). In addition, among women aged 50-69 years who had a mammogram, a significantly higher proportion of Screen Test-EACS clients than Screen Test clients were up to date with both cervical and colorectal cancer screening 3 months after mammogram (107 of 958 Screen Test-EAC clients [11.2\%, $95 \%$ CI $9.2 \%-13.2 \%]$ v. 205 of 6174 Screen Test clients $3.3 \%, 95 \%$ CI $2.9 \%-3.8 \%])$.

\section{Table 1: Women who participated in Screen Test and Screen} Test-EACS

\begin{tabular}{|lcc|}
\hline & \multicolumn{2}{c|}{ Program; no. of women (\%) } \\
\cline { 2 - 3 } Age, yr & Screen Test & Screen Test-EACS \\
\hline $50-69$ & $6174(85.9)$ & $958(88.5)$ \\
\hline $70-74$ & $1011(14.1)$ & $124(11.5)$ \\
\hline Total & $\mathbf{7 1 8 5}(\mathbf{1 0 0})$ & $\mathbf{1 0 8 2}(\mathbf{1 0 0 )}$ \\
\hline Note: EACS & = Enhanced Access to Cervical and Colorectal Cancer Screening. \\
\hline
\end{tabular}

For cervical cancer screening, 322 of 6174 women aged $50-69$ years $(5.2 \%)$ in the Screen Test program and 124 of 958 women $(12.9 \%)$ in the Screen Test-EACS pilot had repeat tests. For colorectal cancer screening, 254 of 7185 women aged $50-74$ years $(3.5 \%)$ in the Screen Test program and 64 of 1082 women $(5.9 \%)$ in the Screen Test-EACS pilot had repeat tests.

Figure 2 shows the cumulative percentage and number of women screened during the study period in relation to the date of mammogram. Among Screen Test-EACS clients, cervical cancer screening uptake increased sharply around the date the client had her mammogram, with a peak of 101 out of 263 clients being screened then $38.4 \%$ of all women screened for cervical cancer) (Figure 2A). Colorectal cancer screening uptake increased among both Screen Test-EACS and Screen Test clients: it peaked in the weeek after mammogram among Screen Test-EACS clients (22 of 243 women, 9.1\%) whereas it was more sustained among Screen Test clients (Figure 2B).

\section{Interpretation}

The Screen Test-EACS pilot project was successful in increasing participation in screening for cervical and colorectal cancer compared with the Screen Test program among women who received a mammogram through the mobile service. Increased uptake resulted in a higher overall prevalence of women up to date with cervical and colorectal cancer screening 3 months after the date of mammogram. Increased participation, however, also resulted in Screen Test-EACS clients having a higher proportion of repeat testing (i.e., undergoing testing for cervical or colorectal cancer again despite being up to date with screening for that type of cancer). Although some of the repeat testing may have been medically indicated (e.g., because the previous sample was unsatisfactory) it is probable that Screen Test-EACS may have

Table 2: Cervical and colorectal cancer screening among Screen Test and Screen Test-EACS clients who had a mammogram through one of these programs during the study period

\begin{tabular}{|c|c|c|c|c|c|c|c|c|}
\hline \multirow[b]{3}{*}{ Variable } & \multicolumn{4}{|c|}{$\begin{array}{c}\text { Program; women aged } 50-69 \text { yr screened for } \\
\text { cervical cancer }\end{array}$} & \multicolumn{4}{|c|}{$\begin{array}{c}\text { Program; women aged } 50-74 \text { yr screened for } \\
\text { colorectal cancer }\end{array}$} \\
\hline & \multicolumn{2}{|c|}{$\begin{array}{c}\text { Screen Test } \\
n=6174\end{array}$} & \multicolumn{2}{|c|}{$\begin{array}{l}\text { Screen Test-EACS } \\
\quad n=958\end{array}$} & \multicolumn{2}{|c|}{$\begin{array}{c}\text { Screen Test } \\
n=7185\end{array}$} & \multicolumn{2}{|c|}{$\begin{array}{l}\text { Screen Test-EACS } \\
\quad n=1082\end{array}$} \\
\hline & No. & $\%(95 \% \mathrm{Cl})$ & No. & $\%(95 \% \mathrm{Cl})$ & No. & $\%(95 \% \mathrm{Cl})$ & No. & $\%(95 \% \mathrm{Cl})$ \\
\hline Total screened ${ }^{*}$ & 623 & $\begin{array}{c}10.1 \\
(9.3-10.8)\end{array}$ & 263 & $\begin{array}{c}27.5 \\
(24.6-30.3)\end{array}$ & 782 & $\begin{array}{c}10.9 \\
(10.2-11.6)\end{array}$ & 243 & $\begin{array}{c}22.5 \\
(20.0-24.9)\end{array}$ \\
\hline $\begin{array}{l}\text { Up to date } 6 \mathrm{w} \text { before } \\
\text { mammogram }\end{array}$ & 2940 & $\begin{array}{c}47.6 \\
(46.4-48.9)\end{array}$ & 464 & $\begin{array}{c}48.4 \\
(45.3-51.6)\end{array}$ & 2150 & $\begin{array}{c}29.9 \\
(28.9-31.0)\end{array}$ & 348 & $\begin{array}{c}32.2 \\
(29.4-35.0)\end{array}$ \\
\hline $\begin{array}{l}\text { Up to date } 3 \text { mo after } \\
\text { mammogram }\end{array}$ & 3241 & $\begin{array}{c}52.5 \\
(51.3-53.7)\end{array}$ & 603 & $\begin{array}{c}62.9 \\
(59.9-66.0)\end{array}$ & 2678 & $\begin{array}{c}37.3 \\
(36.2-38.4)\end{array}$ & 527 & $\begin{array}{c}48.7 \\
(45.7-51.7)\end{array}$ \\
\hline Net increase $\dagger$ & 301 & $\begin{array}{c}4.9 \\
(4.3-5.4)\end{array}$ & 139 & $\begin{array}{c}14.5 \\
(12.3-6.7)\end{array}$ & 528 & $\begin{array}{c}7.4 \\
(6.8-8.0)\end{array}$ & 179 & $\begin{array}{c}16.5 \\
(14.3-18.8)\end{array}$ \\
\hline
\end{tabular}


introduced over-screening, raising concerns about potential harms from the screening tests themselves or from falsepositive results.

The pilot project aimed to remove barriers to cervical and colorectal cancer screening by integrating these services with a mobile mammography program in rural and remote communities in northern Alberta. Mobile services have been effective in delivering preventive services such as breast ${ }^{13,14}$ and cervical $^{15}$ cancer screening, as well as in delivering both of these types of screening together with immunizations. ${ }^{16}$ Given

A

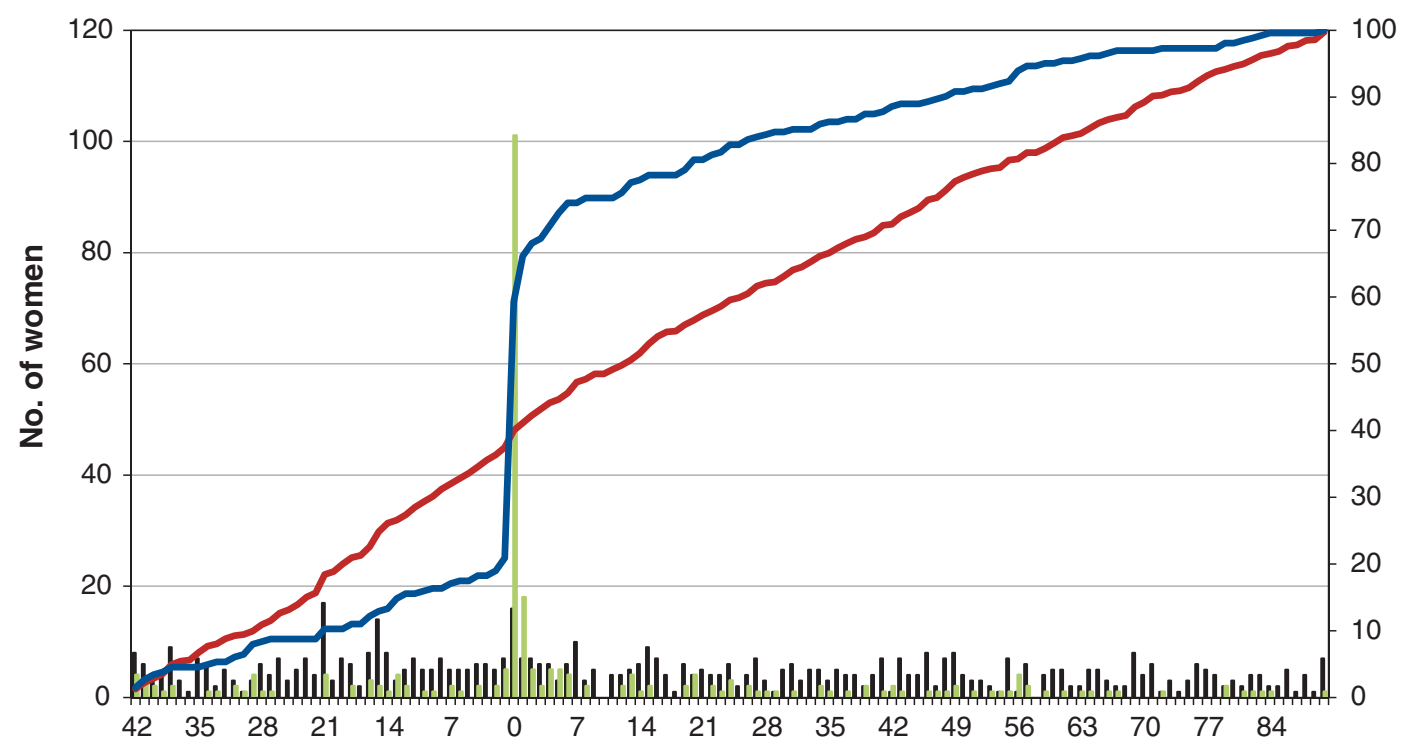

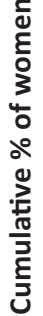

B

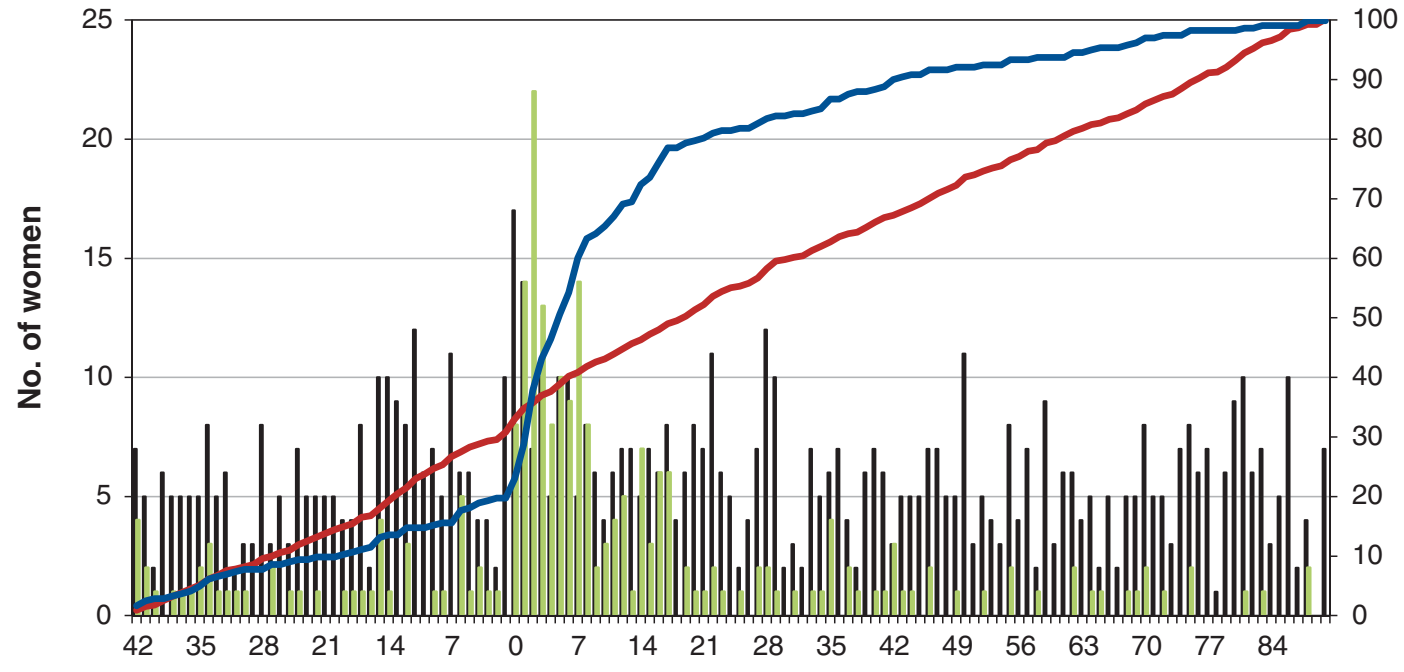

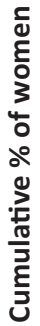

No. of days from breast cancer screening

\begin{tabular}{|l|l|}
\hline $\begin{array}{l}\text { No. of Screen Test clients } \\
\% \text { of Screen Test clients }\end{array}$ & $\begin{array}{l}\text { No. of ScreenTest-EACS clients } \\
\% \text { of Screen Test-EACS clients }\end{array}$ \\
\hline
\end{tabular}

Figure 2: Number and cumulative percentage of (A) women aged 50-69 years screened for cervical cancer and (B) women aged 50-74 years screened for colorectal cancer $(B)$ through Screen Test or Screen-Test-EACS. 
that cancer screening guidelines present some overlap in age eligibility for cervical, breast and colorectal cancer ${ }^{8-10}$ it makes sense to integrate the provision of these 3 types of screening to increase participation. ${ }^{17-19}$

We arbitrarily chose to measure participation 6 weeks before and 3 months after mammogram to ensure the baseline was free of any bias introduced by the recall letters sent a few weeks earlier. The letters included information on cervical and colorectal cancer screening for Screen Test-EACS but not Screen Test clients. Contrary to what we expected, the letters and any promotional events that may have occurred close to the date of the clinic (such as distribution of posters, newspaper advertisements and direct contact including word of mouth) did not seem to prompt clients to get screened in advance, perhaps because of a lack of providers in the community. Most of the Screen Test-EACS clients who participated in cervical or colorectal cancer screening were tested on the day of the mammogram or shortly afterward.

The strengths of this study include data linkage of the 3 provincial cancer screening databases, which contain information on any cancer screening test performed in Alberta. In addition, this paper adds to the scant literature on performance indicators for integrated cancer screening. ${ }^{11}$

\section{Limitations}

Our study has some important limitations. First, communities were not randomly assigned to receive the intervention, which lessens comparability among groups. However, we believe that the results of this evaluation are still relevant and may in fact underestimate the impact of the intervention because communities chosen for the Screen Test-EACS pilot were among the most disadvantaged in the province. Second, communities were not blinded to promotional efforts, which could have led to an increase in cervical and colorectal cancer screening in all communities, ultimately underestimating the true effect of Screen Test-EACS. Third, our study focused on a single screening cycle instead of examining long-term outcomes of increasing access to cancer screening in rural and remote communities. Finally, we do not report screening test results as the study was focused on increasing compliance with provincial schedules.

\section{Conclusion}

The Screen Test-EACS pilot project was more effective than the Screen Test program at increasing the percentage of women up to date with cervical and colorectal cancer screening. This study suggests that an enhanced mobile program that provides client-centred one-stop shopping for breast, cervical and colorectal cancer screening services is effective in increasing uptake. This is probably due to increased awareness through the project's promotional efforts and the removal of geographic and administrative barriers. Future studies should determine the long-term effects of such projects on participation, yield and survival in rural and remote settings in comparison with urban settings, as well as the impact of mobile clinics on participation in colorectal cancer screening by men. Finally, outreach cancer screening initiatives should balance the benefits of increased screening against the risks and costs of over-screening.

\section{References}

1. Zoorob R, Anderson R, Cefalu C, et al. Cancer screening guidelines. Am Fam Physician 2001;63:1101-12.

2. Canadian Population Health Initiative. How bealthy are rural Canadians? An assessment of their bealth status and health determinants. Ottawa: Canadian Institute for Health Information (CIHI); 2006. Available: https://secure.cihi.ca/ free_products/rural canadians_2006 report_e.pdf (accessed 2017 Mar. 29).

3. Kerner J, Liu J, Wang K, et al. Canadian cancer screening disparities: a recent historical perspective. Curr Oncol 2015;22:156-63.

4. Paquette D, Snider J, Bouchard F, et al. Performance of screening mammography in organized programs in Canada in 1996. The Database Management Subcommittee to the National Committee for the Canadian Breast Cancer Screening Initiative. CMA7 2000;163:1133-8.

5. Screen Test. Edmonton: Alberta Health Services; 2017. Available: www.alberta healthservices.ca/info/service.aspx?id=1002353 (accessed 2017 Mar. 17).

6. What works - Cancer prevention and control: cancer screening. Evidencebased interventions for your community. Atlanta: The Community Guide; 2012. Available: https://www.thecommunityguide.org/sites/default/files/ assets/What-Works-Cancer-Screening-fact-sheet.pdf (accessed 2017 Mar. 20).

7. Health plan and business plan 2014-2017. Edmonton: Alberta Health Services; 2014. Available: www.albertahealthservices.ca/assets/about/publications/ahspub-health-business-plan.pdf (accessed 2017 Mar. 29).

8. Breast cancer screening [guidelines]. Edmonton: Toward Optimized Practice; 2015. Available: www.topalbertadoctors.org/cpgs/2886567 (accessed 2017 Mar. 29).

9. Cervical cancer screening [guidelines]. Edmonton: Toward Optimized Practice; 2016. Available: www.topalbertadoctors.org/cpgs/919105 (accessed 2017 Mar. 29).

10. Colorectal cancer screening [guidelines]. Edmonton: Toward Optimized Practice; 2015. Available: www.topalbertadoctors.org/cpgs/30429617 (accessed 2017 Mar. 29).

11. Mema SC, Yang H, Vaska M, et al. Integrated cancer screening performance indicators: a systematic review. PLoS One 2016;11:e0161187.

12. A project ethics community consensus initiative (ARECCI). Edmonton: Alberta Innovates; 2017. Available: www.aihealthsolutions.ca/initiativespartnerships/arecci-a-project-ethics-community-consensus-initiative/ (accessed 2017 Mar. 29).

13. Fontenoy AM, Langlois A, Kegle PL, et al. Performance of mobile units of the Quebec breast cancer screening program, 2002-2009. Am 7 Epidemiol 2011;173:S3.

14. Fontenoy AM, Langlois A, Chang SL, et al. Contribution and performance of mobile units in an organized mammography screening program. Can 7 Public Health 2013;104:e193-9.

15. Swaddiwudhipong $W$, Chaovakiratipong C, Nguntra P, et al. A mobile unit: an effective service for cervical cancer screening among rural Thai women. Int 7 Epidemiol 1999;28:35-9.

16. Alexy BB, Elnitsky C. Rural mobile health unit: outcomes. Public Health Nurs 1998;15:3-11.

17. Leatt P, Pink GH, Guerriere M. Towards a Canadian model of integrated healthcare. Healthc Pap 2000;1:13-35.

18. Emmons KM, Cleghorn D, Tellez T, et al. Prevalence and implications of multiple cancer screening needs among Hispanic community health center patients. Cancer Causes Control 2011;22:1343-9.

19. Integrated health services - What and why? Technical Brief No. 1. Geneva: World Health Organization (WHO); 2008. Available: www.who. int/healthsystems/technical_brief_final.pdf (accessed 2017 Mar. 29).

Affiliation: Alberta Health Services, Cancer Screening Program (Mema, Yang, Elnitsky, Jiang, Xu) and Knowledge Resource Service (Vaska), Calgary, Alta.

Contributors: All authors contributed equally to this study.

Supplemental information: For reviewer comments and the original submission of this manuscript, please see www.cmajopen.ca/content/5/4/ E740/suppl/DC1. 